\title{
Ethanol From Olive Paste During Malaxation, Exploratory Experiments
}

\author{
Piernicola Masella,* Lorenzo Guerrini, Giulia Angeloni, Bruno Zanoni, \\ and Alessandro Parenti
}

Ethanol is a precursor of ethyl esters in olive oil. Its presence is generally ascribed to microbial degradation of damaged olives. At the same time, it is an anaerobic metabolite that naturally accumulates in olive fruit during ripening. As the possible link with olive processing is poorly studied, this laboratory-scale experiment measures gaseous ethanol in the headspace above olive paste malaxated in sealed conditions. Malaxation take place in the presence or absence of oxygen, using sanitized or untreated olives. The findings show that ethanol accumulates in the headspace in oxygenated trials, reaching roughly $80 \mu \mathrm{mol} \mathrm{kg}{ }^{-1}$ of olive paste. Under anoxic conditions ethanol accumulation is ten times higher, while olive treatment is not significant. Ethanol kinetics during malaxation are modeled as a biexponential system in which two components are simultaneously present, originating from parallel reactions at different constant rates. The first is the ethanol present in the olives and gradually released in the headspace. The second is ethanol neoformation under anoxic conditions. Under oxygenated conditions, the first component predominates, while under anoxic conditions, the opposite holds.

Practical Application: Online monitoring of gaseous ethanol above olive paste during malaxation could easily be implemented in olive oil processing plants. Ethanol kinetics could indicate the presence of unwanted anoxic conditions and help in setting appropriate oxygen levels in the kneaded paste. Future studies may find a link between ethanol kinetics in the malaxation headspace, and the occurrence of ethyl esters in oils. If this is the case, operators would be able to fine-tune the process to avoid unwanted effects.

\section{Introduction}

There is an increasing body of scientific literature in the field of extra virgin olive oil processing. The aim is to maximize product quality and identify reliable tools that can modulate quality and preserve, at the same time, extraction efficiency. ${ }^{[1-9]}$ Among the conventional processing steps (washing, crushing, malaxation, centrifugal extraction and clarification, oil filtration) malaxation seems to be crucial. Complex physico-chemical phenomena take place in the olive paste as it is kneaded; these include enzyme activation and activity, hydrolysis and oxidation in both the oil and minor components, oil coalescence, volatile formation, etc. ${ }^{[10]}$ In recent years the scientific literature has focused on a new topic - the occurrence of fatty acid alkyl esters in the oil (methyl and ethyl). ${ }^{[1-18]}$ There is a consensus that their formation is due to esterification and/or transesterification of free fatty acids and low molecular weight alcohols such as methanol and ethanol of both classes of esterification reagents (i.e., acids and alcohols) is ascribed to the degradation of damaged olives. In particular, free fatty acids are thought to be due to lipase activity hydrolyzing olive triglycerides, methanol coming from pectin degradation of cell membranes, while ethanol is thought to be exclusively due to microbiological fermentation.

However, Beltran et al. ${ }^{[19]}$ showed that the origin of ethanol is unclear, and the olive fruit itself is a possible source. According to the latter study, ethanol accumulates in olive fruit during ripening due to the activity of the enzyme alcohol dehydrogenase during the synthesis of anaerobic metabolites (including ethanol). The study also established the cultivar dependency of ethanol production and finally, with respect to ethanol synthesized on the tree, drew some inferences about the potential effect of the harvesting date on ethanol levels in olives, processed paste and finally, virgin oils. Nevertheless, the potential link between olive processing and ethanol is poorly studied. The present work aims to contribute to this topic by testing for the presence of ethanol in the headspace above olive paste during malaxation in sealed conditions. The underlying 
assumption is that olive paste under malaxation acts as a bioreactive system in which multiple chemical and biochemical reactions occur, some of which are reflected in changes in the relative composition of the headspace when the system is sealed. Earlier work has found that, in these conditions, oxygen in the headspace is naturally consumed by the paste and, at the same time, a huge amount of carbon dioxide accumulates in the sealed chamber. ${ }^{[20-22]}$ Following the work of Beltran et al. ${ }^{[19]}$ and the hypothesis that ethanol formation in olive fruit is due to enzymatic activity, the accumulation of headspace ethanol during malaxation in sealed conditions is investigated in a series of trials, in an attempt to better understand the olive/ ethanol association.

\section{Experimental Section}

\subsection{Materials}

The experiment used the cultivar "Frantoio," manually picked near Florence (Tuscany, Italy) in late October 2017. Immediately after collection, drupes were physically intact (undamaged) and in a perfect sanitary condition. A subset of 300 fruits was visually inspected both externally and after dissection for signs of pests or insect infestation, notably olive fly. Maturation was at a medium stage, confirmed by a ripening index of 3.6. ${ }^{[23]}$ The same evaluation procedure was repeated at the begin of each day of trials by sampling a further subset of 300 fruits, checking for any possible variations in the maturation/healthy status. The ripening index does not deviate from the initial value of 3.6 and no sign of alteration was detected.

\subsection{Experimental Procedure and Malaxation Apparatus}

A set of olive paste malaxation trials were carried out in a labscale hermetically sealed malaxator, while the quantity of ethanol vapor in the headspace above the olive paste was continuously measured. A full factorial experimental design was adopted: two factors (malaxation conditions and olive pretreatment) were tested at two levels in four replicates, giving a total of 16 runs (Table 1). The two levels of malaxation conditions factor were: malaxation under anoxic conditions (i.e., without oxygen in the headspace of the malaxation chamber), or malaxation under oxygenated conditions (i.e., the amount of oxygen in the malaxation chamber at the beginning of malaxation was equal to conventional atmospheric conditions, about $20 \mathrm{kPa}$ partial pressure; hence each oxygenated trial has been carried out as a natural malaxation process without oxygen control, but in hermetically sealed conditions). The two levels of olive pretreatments factor were: sanitized olives (treated with potassium metabisulfite), or untreated olives (washed in distilled water).

A homogeneous batch of olives was used. After manual homogenization and distilled water washing, the initial batch was divided into 16 aliquots and randomly assigned to each experimental combination. Trials were performed over four consecutive days, with one complete replicate per day. At all times, olives were stored at a controlled temperature of $3^{\circ} \mathrm{C}$, in the absence of light. In each trial, olives were crushed using a
Table 1. The adopted full factorial experimental design with two factors (malaxation conditions and olive pretreatment) at two levels (oxygenated or anoxic malaxation cross sanitized or untreated olives) in four replicates (total of 16 runs over four days of trials, one complete replicate per day)

\begin{tabular}{|c|c|c|c|c|}
\hline \multirow[b]{2}{*}{ Run } & \multicolumn{2}{|c|}{ Factors } & \multirow[b]{2}{*}{ Replicate } & \multirow[b]{2}{*}{ Trial day } \\
\hline & Malaxation conditions & Olive pretreatment & & \\
\hline 1 & Anoxic & Sanitized olives & 1 & First \\
\hline 2 & Anoxic & Untreated olives & 1 & First \\
\hline 3 & Oxygenated & Sanitized olives & 1 & First \\
\hline 4 & Oxygenated & Untreated olives & 1 & First \\
\hline 5 & Anoxic & Sanitized olives & 2 & Second \\
\hline 6 & Anoxic & Untreated olives & 2 & Second \\
\hline 7 & Oxygenated & Sanitized olives & 2 & Second \\
\hline 8 & Oxygenated & Untreated olives & 2 & Second \\
\hline 9 & Anoxic & Sanitized olives & 3 & Third \\
\hline 10 & Anoxic & Untreated olives & 3 & Third \\
\hline 11 & Oxygenated & Sanitized olives & 3 & Third \\
\hline 12 & Oxygenated & Untreated olives & 3 & Third \\
\hline 13 & Anoxic & Sanitized olives & 4 & Fourth \\
\hline 14 & Anoxic & Untreated olives & 4 & Fourth \\
\hline 15 & Oxygenated & Sanitized olives & 4 & Fourth \\
\hline 16 & Oxygenated & Untreated olives & 4 & Fourth \\
\hline
\end{tabular}

laboratory extrusion mill which gives a slight temperature increase of about $3 \pm 0.7^{\circ} \mathrm{C}$. After crushing, the first and last parts of the resulting paste were discarded, giving a final olive paste amount of about $600 \mathrm{~g}$ to be malaxated. Malaxation took place under sealed conditions in all trails for a period of $900 \mathrm{~s}$ at a controlled temperature of $25 \pm 0.5^{\circ} \mathrm{C}$. In anoxic trials, regardless of olive pretreatment, the headspace of the malaxation chamber above the olive paste was continuously flushed by nitrogen gas before mixing began until oxygen levels fell to zero. In oxygenated trials, regardless of olive pretreatment, the malaxation chamber was sealed after being filled with paste, then malaxation began.

Given that oxygen is consumed during sealed malaxation, ${ }^{[21]}$ our trials were purposely designed to limit, as far as possible, oxygen depletion. The aim was to ensure oxygen availability for the paste in order to emphasize the difference with anoxic trials. Hence, we decided to limit, as far as possible, the amount of paste under malaxation to reduce oxygen consumption. At the same time, a certain amount of olive paste was required for the experiment to be effective. To this end, the ratio of head space volume to paste mass was kept at about 1:1 (roughly $600 \mathrm{~g}$ of paste in a $1200 \mathrm{~mL}$ malaxation chamber). This value is well below that of conventional malaxation, where the malaxer is almost full. For sanitized olive trials, fruit and all laboratory devices (notably the crusher and malaxator) were treated with a highly concentrated solution (10\%) of potassium metabisulfite. In each trial, $1 \mathrm{~kg}$ of olives was submerged for $30 \mathrm{~min}$ in $3 \mathrm{~L}$ of sanitizing solution. Then, olives were washed with distilled water and processed as described above. 
The malaxation apparatus consisted of a stainless steel cylindrical chamber, with $104 \mathrm{~mm}$ internal diameter, $141 \mathrm{~mm}$ height, and internal volume $1200 \mathrm{~mL}$. The chamber was positioned vertically and mounted inside a cylindrical rotating shaft (external diameter $11 \mathrm{~mm}$, height $130 \mathrm{~mm}$ ) equipped with three mixing palettes. The upper and lower palettes were horizontal and mounted in a radial direction $(50 \mathrm{~mm}$ length, $11 \mathrm{~mm}$ wide, $3 \mathrm{~mm}$ thick). The middle palettes were duplicated and mounted in opposite directions at about $40^{\circ}$ with respect to the shaft direction (one upward, one downward; the same size as the others). The shaft was powered by a direct current (12 v) electric motor running at $25 \mathrm{rpm}$. The upper part of the malaxation chamber was hermetically sealed with a removable lid equipped with openings to house sensors (oxygen, ethanol, temperature, and pressure). The chamber was also equipped with a thermostated jacket fitted to a recirculating laboratory water bath.

\subsection{Measurements and Determination}

Gaseous ethanol in the headspace above the olive paste was measured with a gas ethanol sensor (ETH-BTA, Vernier Software $\&$ Technology, USA). Oxygen was measured using a gas oxygen sensor (O2-BTA, Vernier Software \& Technology, USA). Temperature was measured with a temperature probe (GOTEMP, Vernier Software \& Technology). Pressure was measured with a pressure probe (PS400-BTA, Vernier Software \& Technology). All of these sensors were connected to a dedicated datalogger (LabQuest 2, Vernier Software \& Technology), with data recorded at $1 \mathrm{~Hz}$. Gas sensors gave values as a percentage of partial pressure. After taking instantaneous readings of temperature and pressure into account, oxygen and ethanol concentrations were converted to $\mathrm{mol} \mathrm{L}^{-1}$ and scaled to the headspace volume $(600 \mathrm{~mL})$. Hence, oxygen and ethanol data are reported as $\mu \mathrm{mol}$ of gas in the headspace.

\subsection{Statistical Analysis}

The kinetics of ethanol gas in the malaxer headspace were presented by plotting readings against malaxation time. Minimum (min) and maximum ( $\max$ ) readings were derived from the data. The calculation of the area under the curve (AUC) followed a numerical quadrature approach (as a definite integral between 1 and $900 \mathrm{~s}$ malaxation time). These three parameters (min, max, and AUC) were analyzed with a two-way analysis of variance (ANOVA) by studying main effects and the interaction of the two factors (malaxation and olive pretreatment).

Biexponential equations were fitted to average replicate data to determine the most likely model ${ }^{[24]}$ with SigmaPlot 10.0 (Systat Software Inc., USA). This software adopts an iterative approach based on the Marquardt-Levenberg algorithm, and aims to minimize the sum of the squared differences between observed and predicted values of the dependent variable. ${ }^{[25]}$

\section{Results and Discussion}

Ethanol vapor accumulates in the headspace above the olive paste under sealed malaxation. This is clearly shown in Figure 1, graph $\mathrm{A}$, where ethanol moles in the headspace are plotted as a function of kneading time in conventional malaxation conditions with untreated olives and a headspace oxygen concentration at the beginning of malaxation equal to normal atmospheric conditions (about $5670 \mu \mathrm{mol}$, corresponding to $20 \mathrm{kPa}$ ). Ethanol increases rapidly, from an average of about $6 \mu \mathrm{mol}$ at the beginning of malaxation to $50 \mu \mathrm{mol}$ at the end.

Most of the literature reports the main source of ethanol as due to microbiological activity taking place on the olive fruit, especially damaged drupes. However, the olives used in our experiment were in very good sanitary conditions. Specifically, they were manually picked and showed no signs of insect infestation or physical damage. Nevertheless, a set of trials were run to test for any microbiological contribution to ethanol formation. Fruit and all laboratory devices were treated following the procedure used for sanitized olives (with a highly concentrated $10 \%$ solution of potassium metabisulfite) in order to reduce the microbial load. As reported in Figure 1 graph B, the kinetics of ethanol vapor accumulation in the headspace above the olive paste from sanitized olives do not differ from untreated olives, reaching the same average value of $50 \mu \mathrm{mol}$ at the end of malaxation.

On the basis of this evidence, the hypothesis that the microbiological contribution is the principal driver of ethanol formation during malaxation can be confidently discarded. In the first experiment, the observed accumulation of ethanol could be simply ascribed to its release from the olive paste during malaxation, as ethanol was already present in drupes. This is consistent with Beltran et al., ${ }^{[19]}$ who reported that olive fruit itself is a source of ethanol and that its amount strictly depends on the cultivar and ripening. Therefore, it is reasonable to assume that most of the ethanol in the headspace comes from the release of ethanol already present in the fruit. On the other hand, Beltran et al. underline that olives can produce ethanol by means of anaerobic respiration. Ethanol production by fruit under anoxic conditions is a well-known phenomenon, especially in postharvest and packaging studies. ${ }^{[26,27]}$ It is reasonable to assume that the same phenomenon could occur in olive paste, which is a heterogeneous system where vegetal cells maintain their enzymatic and metabolic activity, even after crushing.

To test this hypothesis, a set of dedicated malaxation trials were performed under anoxic conditions by flushing the headspace of the malaxation chamber with nitrogen gas until the oxygen partial pressure was close to $0 \mathrm{kPa}$, for paste from both untreated and sanitized olives (Figure 1 graphs $C$ and D). Regardless of the treatment, under anoxic conditions ethanol accumulation in the headspace was roughly ten times higher than under oxygenated conditions, reaching a mean value of about $500 \mu \mathrm{mol}$ at the end of malaxation. As the sole difference compared to oxygenated trials was the absence of oxygen in the headspace, regardless of the pretreatment process, it is unlikely that the release of ethanol already present in the paste may have been significantly influenced. It is also reasonable to infer that anaerobic respiration takes place in the olive paste as a response to anoxic conditions, increasing ethanol production from paste cells.

Consequently, it is possible to assume that the difference in the amount of ethanol between anoxic and oxygenated trials 

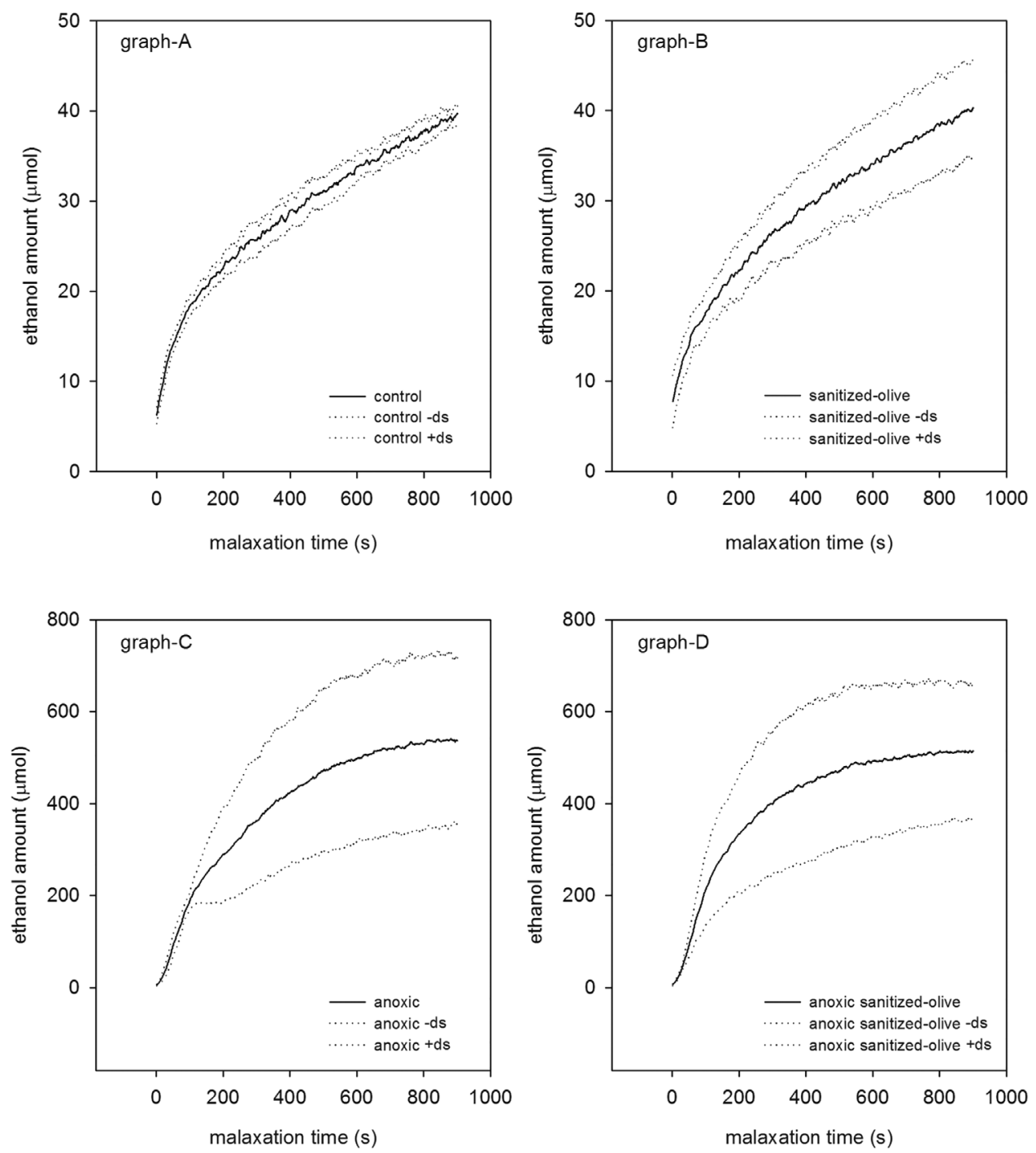

Figure 1. Ethanol kinetics as a function of malaxation time.

could be entirely due to anaerobic respiration. The two-way ANOVA results for minimum and maximum ethanol amounts, together with the AUC, support the hypothesis that ethanol kinetic is strongly affected by anoxic conditions. Table 2 shows that the minimum amount of ethanol, recorded at the beginning of malaxation, does not significantly differ among treatments. The initial ethanol content of the headspace is the same in all trials, corresponding to an average overall value of $6.39 \mu \mathrm{mol}$.

On the other hand, the maximum is significantly affected by anoxic conditions, while neither olive pretreatment nor the twofactor interaction is significant. Specifically, the main effect of malaxation corresponds to a maximum ethanol amount of $534.59 \mu \mathrm{mol}$ under anoxic malaxation, compared to $40.21 \mu \mathrm{mol}$ of oxygenated malaxation. Likewise, the AUC in anoxic malaxation is $4.06 \mathrm{E}+05 \mu \mathrm{mol} \mathrm{s}^{-1}$, compared to $0.29 \mathrm{E}$ $+05 \mu \mathrm{mol} \mathrm{s}^{-1}$ of oxygenated malaxation.

As expected, oxygen in the headspace falls by about $10 \%$ from the beginning to the end of malaxation in oxygenated trials, with no significance difference in the final oxygen amount between control and sanitized olives (two-sample $t$ test, $p>0.05$; Figure 2). This fall is well below what has been generally reported in the literature ${ }^{[28-32]}$ and is consistent with the design of the present experiment. In fact, oxygen consumption by olive paste during malaxation is a well documented phenomenon, ${ }^{[28-32]}$ although a great variation of oxygen kinetics and amounts of oxygen consumption can be noticed, probably because of extremely variable experimental conditions, such as lab-scale or industrialscale, olive variety and ripening degree, malaxation temperature, size and shape of the malaxer, size of the headspace as compared to the amount of olive paste under malaxation, and so on. An overall average of oxygen consumption from this literature may be roughly assessed as $50 \%$ of the oxygen initial value (variation coefficient of $60 \%$ ). This value is well above the $10 \%$ value observed in the present experiment, most likely due to the magnitude of the head space volume compared to paste mass, that is, in our experiment there is little amount of substrate to consume oxygen than in the other experiments. On the other hand, our trials have been purposely designed to limit as far as 
Table 2. Two-way ANOVA results for the area under the curve (AUC), minimum and maximum ethanol amounts in the headspace at the end of malaxation.

\begin{tabular}{|c|c|c|c|c|}
\hline \multicolumn{5}{|c|}{ Results of the two-way ANOVA } \\
\hline Factor & $\begin{array}{l}\text { Degree of } \\
\text { freedom }\end{array}$ & $\begin{array}{c}\text { Mean } \\
\text { squares }\end{array}$ & F-ratio & $p$-value \\
\hline & \multicolumn{4}{|c|}{ Ethanol minimum } \\
\hline Malaxation & 1 & 5.405 & 1.317 & 0.274 \\
\hline Olive pretreatment & 1 & 4.788 & 1.166 & 0.301 \\
\hline $\begin{array}{l}\text { Malaxation } \times \text { olive } \\
\text { pretreatment }\end{array}$ & 1 & 0.673 & 0.164 & 0.693 \\
\hline \multirow[t]{2}{*}{ Error } & 12 & 4.105 & & \\
\hline & \multicolumn{4}{|c|}{ Ethanol maximum } \\
\hline Malaxation & 1 & 977652.572 & 66.737 & 0.000 \\
\hline Olive pretreatment & 1 & 652.735 & 0.045 & 0.836 \\
\hline $\begin{array}{l}\text { Malaxation } \times \text { olive } \\
\text { pretreatment }\end{array}$ & 1 & 724.484 & 0.049 & 0.828 \\
\hline \multirow[t]{2}{*}{ Error } & 12 & 14649.398 & & \\
\hline & & Ethanol AUC & & \\
\hline Malaxation & 1 & $5.671 E+11$ & 60.921 & 0.000 \\
\hline Olive pretreatment & 1 & $1.001 \mathrm{E}+08$ & 0.011 & 0.919 \\
\hline $\begin{array}{l}\text { Malaxation } \times \text { olive } \\
\text { pretreatment }\end{array}$ & 1 & $8.059 \mathrm{E}+07$ & 0.009 & 0.927 \\
\hline Error & 12 & $9.309 \mathrm{E}+09$ & & \\
\hline
\end{tabular}

possible the potential oxygen depletion during oxygenated malaxation, in the attempt to assure oxygen availability for the paste so to emphasize differences against anoxic trials. Accordingly, the magnitude of the observed oxygen depletion does not appear to be relevant to the phenomenon of ethanol accumulation, as seen in the lack of correlation between the amount of oxygen at the end of malaxation and maximum ethanol or ethanol AUC (oxygenated trials, regardless of olive pretreatment, $r$ equal to -0.33 and -0.38 for max and AUC, respectively, $p=0.99$ ). In any case, a deep and exhaustive understand of oxygen consumption by olive paste is still lacking. Masella et al. ${ }^{[20]}$ propose the accelerated paste cells respiration as the main driving phenomenon, being the oxygen consumption coupled with a large amount of carbon dioxide accumulation in headspace of the malaxer. By contrast, Servili et al. ${ }^{[32]}$ state that carbon dioxide emission does not depend on oxygen kinetics, but most likely on the release of carbon dioxide already accumulated in the olive during respiration before processing. Hence, oxygen depletion was mainly ascribed to oxidation of phenols. Of course this matter needs further dedicated studies, but it falls outside the specific topic of the present work, which is focused on ethanol.

Ethanol accumulation in the headspace can be seen as a twocomponent heterogeneous model, ${ }^{[24]}$ where ethanol accumulation results from two, parallel reactions with different constant rates. One component may be the ethanol already present in olive cells and trapped in the olive paste; during malaxation ethanol is gradually released in the headspace. The second component may be ethanol neoformation by anaerobic respiration of olive paste cells, due to anoxic conditions. This system can be modeled by the following biexponential equation:

$\operatorname{ETh}_{(\mathrm{t})}=\underset{\text { max,rel }}{\operatorname{ETh}}\left(1-e^{-R_{1} t}\right)+\underset{\text { max,aresp }}{\operatorname{ETh}}\left(1-e^{-R_{2} t}\right)$

where

$\mathrm{ETh}_{(\mathrm{t})}$ is the ethanol in the headspace at time $t ; \mathrm{ETh}_{(\max , \text { rel })}$ is the maximum ethanol amount due to the simple release of ethanol trapped in the paste (first component); $\mathrm{ETh}_{(\mathrm{max}, \text { a_resp) }}$ is the maximum ethanol amount due to anaerobic respiration (second component); $R_{1}$ and $R_{2}$ are the constants of the two components, respectively; $t$ is the malaxation time.

In the first instance, we could hypothesize that under oxygenated conditions the contribution of anaerobic respiration is negligible. As only the main effect of malaxation is significant (Table 2), we can tentatively fit a single component exponential
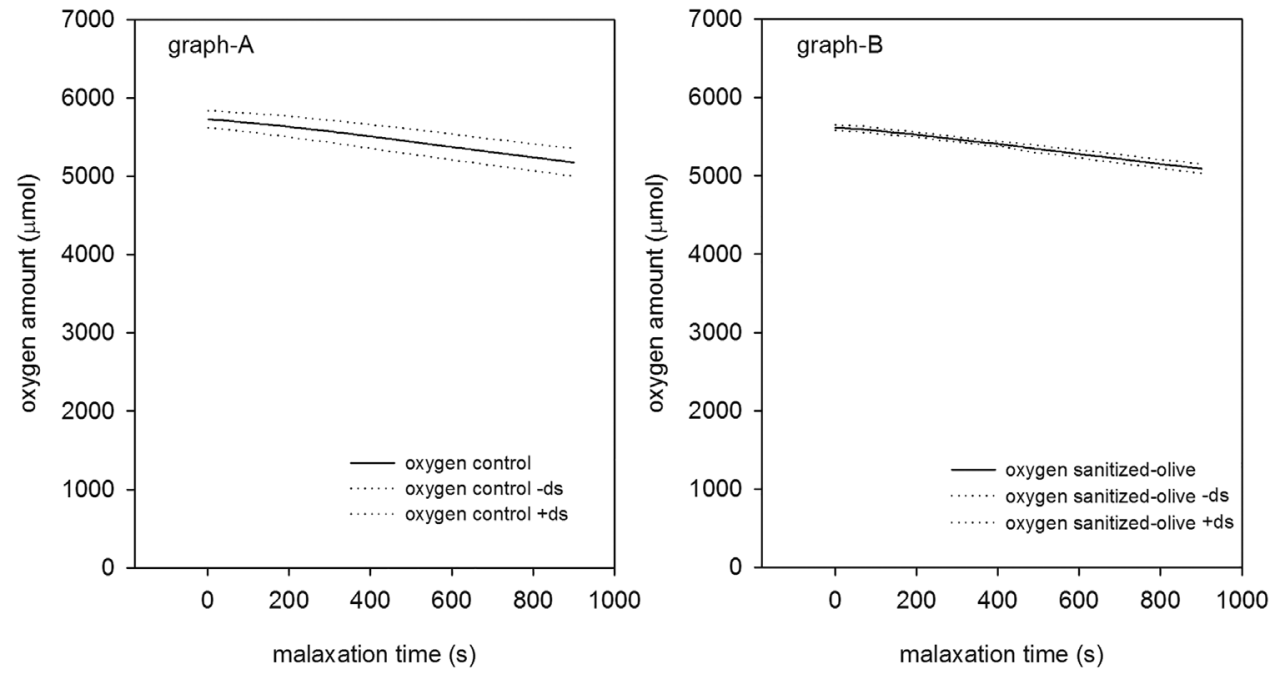

Figure 2. Oxygen kinetics as a function of malaxation time (oxygenated trials). 
Table 3. Parameters describing exponential models fitted to ethanol kinetic.

\begin{tabular}{|c|c|c|c|c|c|c|c|c|c|}
\hline & \multicolumn{3}{|c|}{ Oxygenated trials, exponential } & \multicolumn{3}{|c|}{ Oxygenated trials, biexponential } & \multicolumn{3}{|c|}{ Anoxic trials, biexponential } \\
\hline & Estimated & SE & $p^{\mathrm{a})}$ & Estimated & SE & $\bar{p}$ & Estimated & SE & $p$ \\
\hline Eth (max, rel) & 36.912 & 0.192 & ** & 12.710 & 0.086 & ** & 506.435 & 18.270 & ** \\
\hline $\mathrm{R} 1$ & 0.005 & $8.15 \mathrm{E}-05$ & ** & 0.078 & 0.002 & ** & 0.004 & 0.000 & ** \\
\hline Eth (max, a_resp) & - & - & - & 35.578 & 0.243 & ** & 35.560 & 19.500 & * \\
\hline R2 & - & - & - & 0.002 & 0.000 & ** & 0.012 & 0.004 & $*$ \\
\hline Mean square & $4.99 \mathrm{E}+04$ & & ** & $1.87 \mathrm{E}+04$ & & ** & $5.68 \mathrm{E}+06$ & & ** \\
\hline$R$ square & 0.885 & 2.692 & $* *$ & 0.995 & 0.536 & ** & 0.998 & 6.1681 & $* *$ \\
\hline
\end{tabular}

a) ${ }^{*} p$ at 0.05 significance; ${ }^{* *} p$ at 0.01 significance.

model (see the first term on the right-hand side of ref. [1]) to averaged oxygenated trial data.

Table 3 shows that although this estimate is significant, $R^{2}$ is low (0.88 with a standard error of 2.69). In this case the maximum amount of ethanol $\left(\mathrm{ETh}_{(\max , \text { rel })}\right)$ is estimated as $36.91 \mu \mathrm{mol}$. When the two-component model is fitted to the data, $R^{2}$ increases to 0.99 while the standard error falls to 0.29 . Hence, adding a second component improves the goodness of fit and the model seems to indicate that ethanol from anaerobic respiration has to be considered, although its maximum is quite low $\left(12.71 \mu \mathrm{mol}, \mathrm{ETh}_{(\max , \text { a_resp })}\right)$.

Therefore, it is reasonable to assume that the two components are always present simultaneously, due to local anoxicity in the paste. This is consistent with the already mentioned carbon dioxide emission from the paste, ${ }^{[20,32]}$ which determining anoxic conditions should contribute, also in the present experiment, to the ethanol neoformation due to anaerobic respiration.

The biexponential model can now be fitted to the averaged data over anoxic trials, by forcing the parameter corresponding to the maximum ethanol amount due to paste release at $36.58 \mu \mathrm{mol}$ (i.e., the term computed over oxygenated trials). This choice relies on the assumption that ethanol already present in the olive paste is unaffected by anoxic conditions. As shown in Table 3, the model also holds for anoxic trials, as the regression is significant and $R^{2}>0.998$ (the standard error of the estimate of 6.17). This confirms the biexponential nature of ethanol accumulation in the headspace of the malaxation chamber. There are two, parallel reactions: the release of ethanol already present in the fruit and ethanol neoformation under anoxic conditions.

\section{Conclusions}

To the best of our knowledge, this is the first time that an experiment has measured gaseous ethanol in the headspace above olive paste during malaxation in sealed conditions. Ethanol accumulates in the headspace during malaxation, and its kinetics over time seem to be closely related to the absence of oxygen (i.e., anoxicity). Hence, the observed phenomenon is explained as the result of two, parallel reactions, the simple release of ethanol already present in the fruit, and ethanol neoformation due to anaerobic cell respiration. These results clearly need further investigation, notably by testing the potential link between ethanol in the headspace and the occurrence of ethanol or fatty acid alkyl esters in the corresponding oils. Nevertheless, our observations appear promising and have important potential practical applications, including the use of ethanol kinetics to assess olive ripening, or as an indirect index of anoxicity taking place in the paste.

\section{Conflicts of Interest}

The authors have declared no conflict of interest.

\section{Keywords}

anaerobic respiration, ethyl esters, olive oil, paste kneading

Received: May 21, 2018

Revised: July 24, 2018

Published online: November 23, 2018

[1] V. Andreou, G. Dimopoulos, Z. Alexandrakis, G. Katsaros, D. Oikonomou, S. Toepfl, V. Heinz, P. Taoukis, Innov. Food Sci. Emerg. Technol. 2017, 40, 52.

[2] M. L. Clodoveo, V. Moramarco, A. Paduano, R. Sacchi, T. Di Palmo, P. Crupi, F. Corbo, V. Pesce, E. Distaso, P. Tamburrano, R. Amirante, Ultrason. Sonochem. 2017, 37, 169.

[3] L. Guerrini, P. Masella, G. Angeloni, M. Migliorini, A. Parenti, Eur. J. Lipid Sci. Technol. 2017, 119, 1700223.

[4] L. Guerrini, M. Migliorini, M. Giusti, A. Parenti, Eur. J. Lipid Sci. Technol. 2017, 119, 1600156.

[5] A. Leone, R. Romaniello, A. Tamborrino, X. Xu, P. Juliano, Innov. Food Sci. Emerg. Technol. 2017, 42, 56.

[6] S. Trapani, L. Guerrini, P. Masella, A. Parenti, V. Canuti, M. Picchi, G. Caruso, R. Gucci, B. Zanoni, J. Food Eng. 2017, 195, 182.

[7] A. Tamborrino, S. Pati, R. Romaniello, M. Quinto, R. Zagaria, A. Leone, J. Food Eng. 2014, 141, 1.

[8] L. Guerrini, P. Masella, M. Migliorini, C. Cherubini, A. Parenti, J. Food Eng. 2015, 157, 84

[9] G. Fregapane, M. D. Salvador, Food Res. Int. 2013, 54, 1907.

[10] M. L. Clodoveo, Trends Food Sci. Technol. 2012, 25, 13.

[11] R. B. Gómez-Coca, G. D. Fernandes, M. C. Pérez-Camino, W. Moreda, LWT-Food Sci. Technol. 2016, 66, 378.

[12] R. B. Gómez-Coca, W. Moreda, M. C. Pérez-Camino, Food Chem. 2012, 135, 1205.

[13] M. G. Di Serio, L. Giansante, G. Di Loreto, A. Faberi, L. Ricchetti, L. Di Giacinto, Food Chem. 2017, 219, 33. 
[14] S. Alcalá, M. T. Ocaña, J. R. Cárdenas, M. Á. Miquel, J. Vilar, F. Espínola, M. Moya, Eur. J. Lipid Sci. Technol. 2017, 119, 1600026.

[15] L. García-Vico, A. Belaj, L. León, R. Rosa, C. Sanz, A. G. Pérez, Food Control 2018, 91, 248.

[16] H. Jabeur, A. Zribi, R. Abdelhedi, M. Bouaziz, Food Chem. 2015, 169, 289.

[17] M. Biedermann, A. Bongartz, C. Mariani, K. Grob, Eur. Food Res. Technol. 2008, 228, 65.

[18] G. Beltran, R. Sánchez, A. Sánchez-Ortiz, M. P. Aguilera, M. A. Bejaoui, A. Jimenez, J. Sci. Food Agric. 2016, 96, 3801.

[19] G. Beltrán, M. A. Bejaoui, A. Jimenez, A. Sanchez-Ortiz, J. Agric. Food Chem. 2015, 63, 5309.

[20] A. Parenti, P. Spugnoli, P. Masella, L. Calamai, Eur. Food Res. Technol. 2006, 222, 521.

[21] A. Parenti, P. Spugnoli, P. Masella, L. Calamai, O. L. Pantani, Eur. J. Lipid Sci. Technol. 2006, 108, 904.

[22] P. Masella, A. Parenti, P. Spugnoli, L. Calamai, J. Am. Oil Chem. Soc. $2011,88,871$.
[23] M. Uceda, L. Frias, In Proceedings of the II Seminario Oleícola Internacional, International Olive Oil Council, Cordoba 1975.

[24] S. A. Bobrovnik, J. Biochem. Biophys. Methods 2000, 42, 49.

[25] D. W. Marquardt, J. Soc. Ind. Appl. Math. 1963, 11, 431.

[26] E. Pesis, Postharvest Biol. Technol. 2005, 37, 1.

[27] R. Botondi, V. Russo, F. Mencarelli, Postharvest Biol. Technol. 2012, 64, 83.

[28] P. Catania, M. Vallone, A. Farid, C. De Pasquale, J. Food Eng. 2016, 169, 179.

[29] P. Catania, M. Vallone, F. Pipitone, P. Inglese, G. Aiello, G. La Scalia, Biosyst. Eng. 2013, 114, 1.

[30] A. Leone, R. Romaniello, R. Zagaria, A. Tamborrino, Biosyst. Eng. 2014, 118, 95.

[31] A. Tamborrino, S. Pati, R. Romaniello, M. Quinto, R. Zagaria, A. Leone, J. Food Eng. 2014, 141, 1.

[32] M. Servili, A. Taticchi, S. Esposto, S. Urbani, R. Selvaggini, G. Montedoro, J. Agric. Food Chem. 2008, 56, 10048. 